\title{
Genistein directly represses the phosphorylation of STAT5 in lactating mammary epithelial cells
}

Yusaku Tsugami ${ }^{1}$, Haruka Wakasa ${ }^{2}$, Takanori Nishimura ${ }^{2}$, and Ken Kobayashi ${ }^{2 *}$

${ }^{1}$ Laboratory of Animal Histophysiology, Graduate School of Integrated Sciences for Life, Hiroshima University, 1-4-4 Kagamiyama Higashi-Hiroshima 739-8528, Hiroshima, Japan

${ }^{2}$ Laboratory of Cell and Tissue Biology, Research Faculty of Agriculture, Hokkaido University, North 9, West 9 060-8589, Sapporo, Japan

${ }^{*}$ Corresponding author: Ken Kobayashi, Ph.D.

Laboratory of Cell and Tissue Biology, Research Faculty of Agriculture, Hokkaido University, North 9, West 9 060-8589, Sapporo, Japan

Phone: +81-11-706-2540, FAX: +81-11-706-2540

E-mail: kkobaya@anim.agr.hokudai.ac.jp 

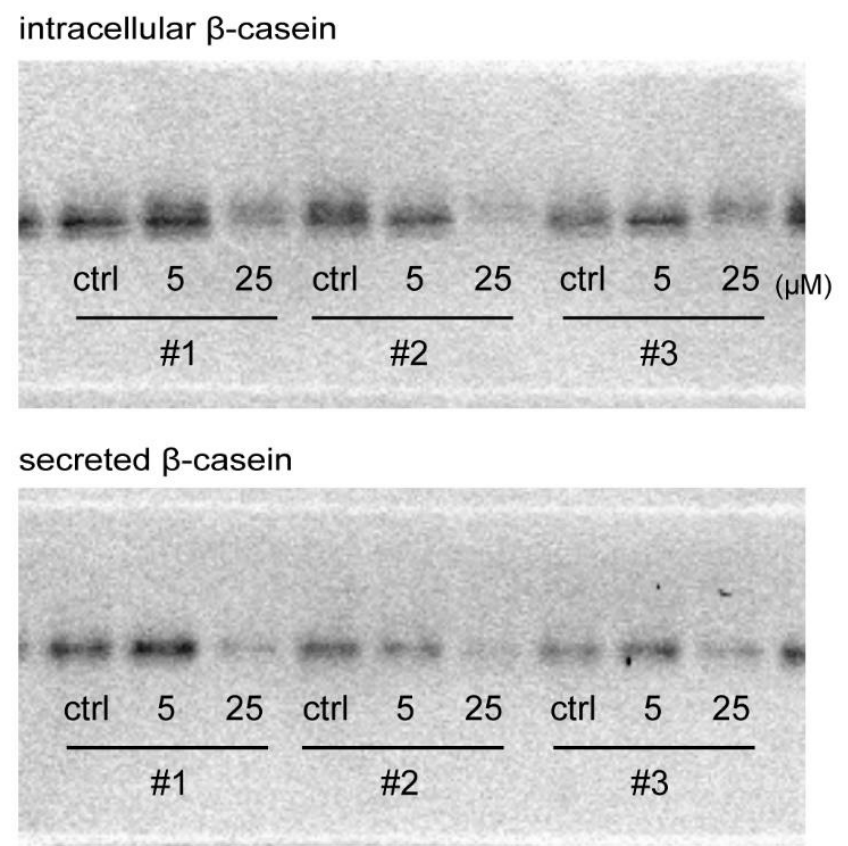

\section{Figure S1}

The images show the representative membranes detected by western blot. The bands show intracellular or secreted $\beta$-casein at low magnification with other duplicate results (\#1, \#2, \#3). For the quantification, the bands were densitometry analyzed using Quantity One software, and data shows the relative value based on control normalized by $\beta$-actin. The other proteins were also detected and quantified as same. 